\title{
Good Sellers Drive out Bad Sellers: Should We Require Consumers Protection
}

\author{
Maruf Rahman Maxim
}

\begin{abstract}
The point of departure of this paper is a market which is characterized by both heterogeneously rational buyers and sellers. In a stylized model we show that good sellers would drive out bad sellers, if consumers turn rational and the rational buyers impose a cost on the bad seller. In such a market, we argue, an institutional intervention to protect the welfare of consumers may be counter-productive.
\end{abstract}

\section{Introduction}

Modern microeconomics has placed a great deal of emphasis on the rationality of agent in order to examine market mediate outcomes. Most of these works focus on the degree of rationality of a consumer. Fisher (1970) assumes that all consumers are instrumentally rational and demonstrate that the market outcome quickly converges to the competitive equilibrium. Diamond (1971) shows, on the contrary, that sellers acquire monopoly power if the consumers are irrational. Stiglitz (1977) considers a market which is characterized by heterogeneity of consumer's rationality. They conclude that monopolistic sellers, in such a market, practice price discrimination to split the market and to charge a higher price to the submarket of relatively "irrational" consumers. All these works based on the assumption that the rationality, or irrationality, of a consumer arises as a result of some exogenous factor and therefore by definition they rule out the possibility that the irrational consumer can become rational. We consider a market which as heterogeneously rational consumers as well as heterogeneously rational sellers. We posit that the consumers may initially be irrational but they achieve the "rationality" over time which is a fallout of Arrow's (1962) learning path. In such a market the rationality of consumers inflicts a cost on an irrational seller.1 We establish, in a stylized model, the counter-intuitive result that the consumer gains from the improvement of the seller's degree of rationality. The main implication of the result is that good sellers drive out bad sellers if consumers become rational. This result does suggest that, under certain circumstances, institutional intervention (such as consumers' Protection Authority) is detrimental since such an institutional response may adversely affect the learning path of the consumers which in turn, prevents the sellers from reaching a satisfactory level of rationality. As a result, quite ironically, these customers suffer from the institutional intervention which is supposed to protect their welfare.

The plan of the paper is the following: In section the next section we describe the price and quantity policies of different types of sellers and delineate a backlash by consumers if some sellers are myopic. In section III we argue that even if myopic sellers behave rationally in the post-backlash periods, they are driven out by consistently rational sellers.

\section{The Model}

We consider two types of sellers. First, a seller is irrational if he is shortsighted in the sense that he maximizes his short run profit. Contrariwise a seller is rational if he is both forward and backward looking. Such a seller maximizes the long run profit. We assume that consumers are initially irrational while they attain rationality subsequently. We try to hypothesize sellers operation in the following time frame: there are three stages. Stage 1 is the time frame when all buyers/consumers are irrational and a seller may either be rational or irrational. In stage II the business reaches its peak while the demand for the product is very high. Consumers are still irrational. In stage III consumers, on the basis of their prior market experiences, attain rationality and abstain from the short-sighted sellers. 2

Decision making by a short-sighted seller-

This seller maximizes his short run profit without considering its long run impact. His optional price quantity decisions became period specific.

\footnotetext{
${ }^{1}$ As Arrow (1968) pointed out that, "The argument that a set of firms can form a monopoly overlooks the possibility that the consumers can also form a coalition, threaten not to buy, and seek mutually advantageous deals with a subset of the firm, such deals are possible since the monopoly allocation violates some marginal equivalence."

${ }^{2}$ The model turns on a specific backlash induced by group buyers which blindly sets a cost on sellers at stage III which is similar to the suggestion of Arrow.
} 
Stage I - From the short run profit maximization of a monopolist we yield.

$$
\begin{aligned}
& \mathrm{p}^{*}=\frac{\mathrm{e}}{\mathrm{e}-1} \cdot \mathrm{c} \ldots \ldots . . .\left(\mathrm{A}_{1}\right) \\
& \mathrm{q}^{*}=\mathrm{f}^{-1}\left(\frac{\mathrm{e}}{\mathrm{e}-1} \cdot \mathrm{c}\right) \ldots \ldots \ldots\left(\mathrm{A}_{2}\right)
\end{aligned}
$$

$\mathrm{P}^{*}$ and $\mathrm{q}^{*}$ are the optional price and quantity, $\mathrm{c}$ is the marginal cost of production, $\mathrm{e}$ is the elasticity of demand and $\mathrm{f}(\mathrm{q})$ is the inverse demand function prevailing in stage $\mathrm{I}$.

Stage II - The period-specific short run profit maximization yield the following:

$$
\begin{aligned}
& \mathrm{p}=\frac{\mathrm{e}}{\mathrm{e}-1}(\mathrm{c}+\mathrm{L}) \ldots \ldots \ldots \ldots \ldots . .\left(\mathrm{B}_{1}\right) \\
& \mathrm{q}=\mathrm{g}^{-1}\left[\frac{\mathrm{e}}{\mathrm{e}-1}(\mathrm{c}+\mathrm{L})\right] \ldots \ldots \ldots \ldots \ldots\left(\mathrm{B}_{2}\right)
\end{aligned}
$$

$\mathrm{p}$ and $\mathrm{q}$ are optimal price quantity decisions. $\mathrm{L}$ is the maintenance cost, e is the new and lower elasticity of demand, $\mathrm{g}$ is the inverse demand function in stage II, we assume that the business reaches its peak in stage II hence the fall in e is more than balanced by the rise in cost through $\mathrm{L}$.

Stage III - We assume that a seller produces output $\mathrm{Q}_{O}$ at stage I at a marginal cost. At stage III consumers backlash result in a cost on the short-sighted sellers. We assume that as a result of this backlash the short-sighted seller has little option other than to reduce his prices of the product. Let $\left(\mathrm{p}^{*}-\mathrm{x}\right)$ be the price of the produce in stage III while $\mathrm{p}^{*}$ is the price in stage I. Consumers, by assumption inflict this cost on the sellers irrespective of their degrees of rationality. The short-sighted sellers do not realize this cost and end with the following profit:

$$
\pi_{3}=\left(Q_{0}-q^{*}-q\right)\left(p^{*}-x\right)-(c+2 L)
$$

While $\mathrm{Q}_{0}$ is the initial production.

\section{Optimal Decisions of a Dynamic Monopolist -}

We assume that the seller is far-sighted and has precise knowledge in relation to the current demand, the future demand and the possible consumers' backlash. In such a circumstance, he adopts the logic of backward induction. We shall show that the monopolistic profit in stage I and the enforced profit $\pi_{3}$ is less than the competitive profit while the monopolist sets a price which clears the local monopoly market.

In such an event a seller avoids selling his product in stage III in order to escape from the backlash. A short-sighted seller does not foresee this cost. A far-sighted seller makes price and quantity decision to evade it by casting a forward look. He first calculates his optimal price, quantity decisions in stage II and then sets the competitive price to clear the market in stage I. So, he makes the mental calculation concerning stage II:

Stage II: He monopolistically exploits the market by charging

$$
\begin{aligned}
& \mathrm{p}=\frac{\mathrm{e}}{\mathrm{e}-1}(\mathrm{c}+\mathrm{L}) \ldots \ldots \ldots \ldots\left(\mathrm{D}_{1}\right) \\
& \mathrm{q}=\mathrm{g}^{-1}\left[\frac{\mathrm{e}}{\mathrm{e}-1}(\mathrm{c}+\mathrm{L})\right] \ldots \ldots \ldots \ldots . .
\end{aligned}
$$

The rational sellers future sale is $\mathrm{q}$ in stage II while he has to market $\left(\mathrm{Q}_{0}-\mathrm{q}\right)$ either in stage $\mathrm{I}$ or in stage III. Assuming consumers backlash to be effective, a rational seller markets all $\left(\mathrm{Q}_{0}-\mathrm{q}\right)$ in stage I by lowering the price to $\mathrm{p}$ which is less than the monopolistic price $\mathrm{P}^{*}$. Hence a rational seller does not sell anything in stage III, thereby avoiding plausible consumer backlash. On the other hand, a short-sighted monopolist attempts to exploit the market both in stage I and stage II and as a result is unable to avoid the backlash in stage III which he fails to foresee. Based on these intuitions, we provide the following proposition.

Proposition 01: If the consumers' backlash is credible, the profit of a rational seller from stage I is greater than the profits an irrational seller acquire in stage I and stage III.

Proof: Suppose, without any lost of generality that $\mathrm{Q}_{0}=100$ and $\mathrm{q}=50$. Hence $\mathrm{Q}_{0}-\mathrm{q}=50$

$$
\text { then } \mathrm{q}^{*}=\arg \max (\mathrm{pq}-\mathrm{cq})
$$




$$
\begin{aligned}
& \text { and } \mathrm{p}^{*}=\mathrm{f}\left(\mathrm{q}^{*}\right) \\
& \text { hence, } \pi_{1}=\mathrm{p}^{*} \mathrm{q}^{*}-\mathrm{cq} *
\end{aligned}
$$

While $\pi_{1}^{*}$ is the monopolistic profit in stage I.

Then the profit in stage III is given by:

$$
\pi_{3}=\left(p^{*}-x\right)\left(50-q^{*}\right)-\left(50-q^{*}\right)(c+2 L)
$$

When $\mathrm{x}$ is the decline in price following a backlash (or where $\mathrm{x}$ represents the actual deviation from the initial price as a result of backlash).

For a forward looking, rational seller the profit $\pi_{1}$ in stage $\mathrm{I}$ is the following:

$$
\pi_{1}=\left(\mathrm{p}^{*}-\varepsilon\right) .50-50 . \mathrm{C}
$$

When $\varepsilon$ is the decline in the price in stage I as seller becomes competitive. As the decline in price is larger, the larger is the proportion of rational sellers in the market.

If the seller is irrational, his total profit from stage I and stage II is the following:

$$
\begin{aligned}
& \frac{2}{\Sigma \pi}=\pi_{1} *+\pi 3 \\
& \mathrm{i}=1
\end{aligned}
$$

Or, $\frac{2}{\Sigma \pi}=50\left(\mathrm{p}^{*}-\mathrm{c}\right)-\left(50-\mathrm{q}^{*}\right)(\mathrm{x}+2 \mathrm{~L})$

Now if the backlash is effective, then the profit a rational seller made from stage I should be greater than the profits from stage III acquired by an irrational seller. Otherwise, the backlash helps an irrational seller obtain a higher profit.

This is patently not the objective of buyers.

The backlash to be effective requires the following:

$$
\pi_{1}>\pi_{1} *+\pi_{3}
$$

This implies that a rational seller makes an overall higher profit vis-a-vis an irrational seller. After simple manipulations, condition (3) reduces to the following:

$$
\begin{aligned}
& \quad\left(\mathrm{p}^{*}-\varepsilon\right) 50-50 \mathrm{c}>50\left(\mathrm{p}^{*}-\mathrm{c}\right)-\left(50-\mathrm{q}^{*}\right)(\mathrm{x}-2 \mathrm{~L}) \\
& \text { or, } \quad \mathrm{x}>\frac{50}{50-\mathrm{q}^{*}} \varepsilon-2 \mathrm{~L}
\end{aligned}
$$

On the other hand, if the threat of a backlash is credible then consumers must pay less to the rational sellers for the same quantity $\left(\mathrm{Q}_{0}-\mathrm{q}\right)=50$. This implies.

$$
\mathrm{p}^{*} \mathrm{q}^{*}+\left(\mathrm{p}^{*}-\mathrm{x}\right)\left(50-\mathrm{q}^{*}\right)<50\left(\mathrm{p}^{*}-\varepsilon\right)
$$

Or, $\quad x>\frac{50}{50-q^{*}} \varepsilon$

A comparison between (4) and (5) makes it obvious that if the backlash is credible, it imposes a cost on an irrational seller which makes the profit of a rational seller greater than the net profit of an irrational seller. Since the irrational seller is not forward looking, hence, at stage III, he confronts the cost of backlash. The principle issue thus remains whether such a backlash can effectively eject irrational sellers from the market or not. We attempt to provide a tentative answer to this question in the next section.

Proposition 02: If the market is characterized by only rational sellers, the price in stage I will be lower and the output sold in stage I will be higher ceteris-paribus. The profits of the sellers would be higher and the consumer's surplus would be higher. Hence, if the degree of rationality of a seller improves, it leads to a pareto improvement.

\section{The dynamics of pricing policy: The exit of an irrational seller}

In stage III the sellers form two clear groups. First, the rational sellers who do not sell any products in stage III and hence do not alter their prices. Secondly, the irrational sellers who still try to sell $\left(\mathrm{Q}_{0}-\mathrm{q}-\mathrm{q}^{*}\right)$. We assume that the consumers' backlash results in a lower demand which immediately prompts the irrational sellers to reduce their prices. As they reduce prices, it has a cost on the irrational sellers. One may argue, following the footsteps of stiglitz (1987), that a lower price implies a lower quality and hence a lowering of the price inflicts a 
cost on the seller. Hence, if consumers judge the quality by price after having reached rationality, price falls become costly for the irrational sellers.

One may rationalize the cost associated with price change in a different way. In our model a rational seller adopts two prices $\mathrm{p}, \mathrm{p}^{\wedge}$ in stage I and stage II respectively. The rational consumers have $\mathrm{p}, \mathrm{p}^{\wedge}$ as the common knowledge in stage III while théy become rational. Any other price, ceteris-paribus, embodies a departure from rationality which in turn results in consumers' backlash. Hence, the irrational sellers confront a price adjustment cost in stage III due to the backlash, as the consumers use a price change as an indicator of the degree of rationality of a seller. We assume, the cost of price adjustment $\mathrm{K}$ is given by a quadratic cost function,

$\mathrm{K}=-\mathrm{k}\left(\right.$ Pit - pit-1) $-1 / 2 \mathrm{~d}^{2}(\text { pit }- \text { pit }-1)^{2}$

for $\mathrm{K}>\mathrm{o}, \mathrm{d}>\mathrm{O}$

Now as the sellers face the backlash, they may have two responses. First the sellers may still ignore the backlash and try to exploit the market. Since the consumers are now fully rational, such an attempt may incur a heavy cost on a seller which forces his exit. More importantly, a seller may not turn forward looking as he realizes the impact of his current price decisions of future profits. In this section we concentrate on such a seller who has been irrational in stage I and stage II and now becomes a dynamic agent.

We make a few simplifications to examine his pricing policy. We assume that the demand condition in stage I and stage II are identical and hence he charged a price pit-1 in stage I and II. In stage III, which we call period $t$, he chooses $\mathrm{pt}$ when $\mathrm{t}$ is an infinite horizon $\mathrm{t}=1,2 \ldots \ldots$ to maximize the discounted value of all future profit streams $\pi_{\mathrm{it}}$ :

$$
\Sigma \pi_{\text {it }}(1+\mathrm{r})^{-\mathrm{t}}
$$

where $\pi_{\text {it }}=\mathrm{P}$ it q it $-\mathrm{c}$ qit $+[-\mathrm{k}(\mathrm{p}$ it $-\mathrm{p}$ it- 1$)$

$\left.-1 / 2 d^{2}(P \text { it }- \text { Pit- } 1)^{2}\right]$

In (7) and (7a) $\mathrm{r}$ is a discount rate, $\mathrm{c}$ is the marginal cost and $\pi$ it is the profit net of the cost of production and price adjustment cost in period $t$.

We assume that pit is given along an inverse demand function which is linear:

$$
\text { Pit }=\mathrm{m}-\mathrm{n} \text {. qit }
$$

The Nash equilibrium in price is guaranteed by the following condition:

$$
\pi \mathrm{it} / \mathrm{pit}+(1+\mathrm{r})^{-1} \pi \text { it }+1 / \mathrm{sp} \text { it }=0, \mathrm{t} \geq \mathrm{o}
$$

Since $\pi$ it $/$ sp it $=m-2 n$ pit $+c n-k-d($ pit - Pit-1)

and $\frac{\pi \mathrm{it}+1}{\mathrm{Pit}}=-\mathrm{k}+\mathrm{d}($ pit - Pit-1)

We derive the pricing decision as the following:

$\mathrm{m}-2 \mathrm{n}$ Pit $+\mathrm{c} \mathrm{n}-\mathrm{k}-\mathrm{d}$ (Pit - Pit-1)

$+(1+\mathrm{r})-1[\mathrm{k}+\mathrm{d}(\mathrm{Pit}+1-\mathrm{Pit})]=0$

(8) is a difference equation which shows that the current price pit depends on prices chosen in the past (pit-1) and in the future (Pit+1). Based on this pricing decision function we provide the following proposition:

Proposition 03: If a seller adopts the optimal pricing policy given by difference equation (8), he consistently charges a higher price than what a fully rational seller does. Hence, such a seller is driven out by a fully rational seller over time.

Proof: Write the difference equation as

When

$$
\text { Xt }-\alpha . P i t+\text { Pit- } 1+(1+r)^{-1} \text { Pit }+1 \leq 0
$$

$$
\begin{aligned}
& \mathrm{Xt}=\left(\mathrm{m}-\mathrm{c} \mathrm{n}-\mathrm{k}+(1+\mathrm{r})^{-1} \mathrm{k}\right) / \mathrm{d} \\
& \alpha=\left(-2 \mathrm{n}+\mathrm{d}+\frac{1}{1+\mathrm{r}} \cdot \mathrm{d}\right) .
\end{aligned}
$$

This is a second-order difference equation, in order to solve it we follow sargent (1987).

Let Pit $=\mathrm{B}(\mathrm{Pit}-1+\mathrm{Yt})$

Hence Pit $+1=B(P i t+Y t+1)=B^{2}(P i t-1+Y t+B y t+1)$

Substituting this in the difference equation (A) we get:

$$
\begin{aligned}
& \mathrm{Xt}+\mathrm{B}(\mathrm{Pit}+\mathrm{Yt})\left[(1+r)^{-1} \cdot \mathrm{B}^{2}-\alpha \mathrm{B}+1\right]-\mathrm{Yt} \\
& +\mathrm{B}(1+\mathrm{r})^{-1} \cdot \mathrm{Yt}+1=0
\end{aligned}
$$

The smallest roof of the quadratic equation $(1+r)^{-1} B^{2}-\alpha B+1$

$=0$ is given by: 


$$
\begin{aligned}
& \mathrm{B}^{*}=\left[\frac{\mathrm{a}-\left(\mathrm{a}^{2}-4(1+\mathrm{r})-1\right)^{1 / 2}}{2(1+\mathrm{r})^{-1}}\right] \\
& \mathrm{B}^{*}=\frac{\alpha \cdot(1+\mathrm{r})-\left[\mathrm{a}^{2}(1+\mathrm{r})^{2}-4(1+\mathrm{r})\right]^{1 / 2}}{2}<1
\end{aligned}
$$

Setting $B=B *(2.5)$ reduces to:

$$
\mathrm{Yt}=\mathrm{B}(1+\mathrm{r})^{-1} \text {. Y } \mathrm{t}+1+\mathrm{Xt}
$$

The unique bounded solution of (10) is given by:

$$
\alpha
$$

$$
\begin{aligned}
\mathrm{Yt} & =\Sigma[\mathrm{B}(1+\mathrm{r})-1]^{\alpha} . \mathrm{Xt}+\mathrm{j} \\
\mathrm{j}=0 &
\end{aligned}
$$

Substituting (11) in (b) we get

$$
\text { Pit }=\text { B . Pit-1 }+B \Sigma[B(1+r)-1] \alpha . \underset{j=0}{X t+j}
$$

Equation (12) demonstrates that the current prices of the seller will be a convex combination of the prior price Pt-1 and the expected demand shift and costs. If all firms anticipate identical shifts in demand, the costs of a previously irrational seller are higher. Since Pit-1 of a previously irrational seller is also higher; the price profiles of such a seller would persist to be above that of a fully rational seller.

As a result, even if an irrational seller turns rational at stage III, his prices are consistently above the price profile of a rational seller. Hence, the cost of irrationality at stage I would materialize through time and he has to leave the market. And in the long run only fully rational sellers would be able to survive. In this sense the irrational price decisions are irreversible and good sellers drive out the bad sellers if the consumers are vigilant enough to impose a quadratic price adjustment cost on the sellers.

If the learning path of consumers is blocked by the institutional response, such a consumer backlash fails to materialize which jeopardizes the market process of clearing the bad sellers.

The above analysis suggests the probable outcomes for the irrational seller, assuming Arrow's learning path is operative among consumers. They are as follows:

(a) If an irrational seller faces the consumer backlash in stage III, he has no alternative other than to reduce the price. This in turn may send a misleading signal to consumers in relation to the quality of his product, and as a result he has to reduce the price further if he wants to clear his stock. If he does not, it implies that at the end of stage III he will be left with an unsold stock which means he will not only incur a revenue loss but he has to carry further maintenance costs for the unsold stock. In either case it suggests that the irrational seller's profit from stage I and III will be less than he would have achieved had he undertaken a competitive price at stage I. This then suggests that the skimming price.

(B) If he decided to become rational in period two, he has to undertake additional selling costs, which are incurred as a result of an attempt to overcome his bad reputation from the previous period. This turn will force his cost curve to move upward and consequently his price will remain higher than that of a seller who has followed the rationality path from the beginning. Therefore he will be subject to the backlash again at stage III of period two.

Either little option other than to leave the market because of his inappropriate decision at stage I.

The above argument implies that the irrational seller can gain for a very short period by making some consumers to lose, in our case in the specified stage I. However as consumers travel through the time path they will learn that the irrational seller's price does not correctly signal the quality of his produce (assuming a free flow information). Thus there will be a backlash in stage III, and as a result he has no other option other than to reduce the price well below the competitive price that is charged by a rational seller in stage I. This causes the irrational seller to derive a lower profit from the sum of stage I and III relation to the rational seller's stage I. The reasons are quite obvious, as due to his higher prices in relation to the rational seller, in stage I he would sell much less than that of his counterpart, a reason for which he has left over in the stage III. As a result the irrational seller's average price from stage I and III remains below that of the rational seller of stage I. Thus he incurs a loss. However, the rational seller, who appears to sell at a monopoly price at stage II, has no remaining stock in stage III thereby avoiding the backlash. If we interpret the above result in the light of real phenomena an interesting incidence can be observed. That is although the rational seller charges monopoly price in stage II, the only difference is that the reputation which he derives from stage I permits him to enjoy a greater market share. This in turn enables him to achieve greater economics of scale, thereby reducing costs, he does not pass it on to the consumer. He thereby enjoys the greater difference between the price and production costs. As the consumer loss or gain is largely subjective, if a price does not change, this issue of monopoly price does not 
arise, since consumer are not aware of the rational sellers lower cost of production at stage II this then suggests that those entrepreneurs who maximizes the consumer's gain in the short run will also maximize their own gain in the long run. Alternatively, we can say that those entrepreneurs who deceive their customers in order to maximize their own gain, will be driven out ultimately by the good sellers. This raises an interesting question: if the process of market mechanism shows that there is sufficient force which tends towards self correction, do we need additional institutional organization to increase the speed of this self correcting mechanism? In other words do we need consumer protective organizations of the type that exists in Australia. It will be argued below that if we assume that consumers over time can become rational, then our argument suggests that the social cost of maintaining these organizations may at time exceed the benefit they provide. If a consumer realizes that he/she has been deceived due to his/her irrationality this in itself suggests that the consumer cannot remain irrational permanently, and they will undertake their own self correcting mechanism. This is similar to Arrow's (1962) learning mechanism, where Arrow argues that as the factors of production learn the production process and become more efficient, the average costs per unit tend to decline over time, and he called this relationship "learning by doing". That is as consumers lose they learn the cost of their irrationality and thereby will undertake measures that prevent them from suffering a subsequent loss. This is a natural self correcting mechanism which every consumer normally undertakes. Given the dynamic nature of this self-learning process, if an additional institutional factor has been allocated to speed up this process of learning, three factors need careful consideration. They are as follows:

(a) If the cost of providing information about those businessman who deceive consumers is greater than the cost that will incur in future from a further consumer loss, the social cost may exceed the benefit that can accrue from the existence of the institutional organization. This is based on the assumption that due to the free flow of information, future consumers will learn from the already deceived consumers and the deceived consumers already have undertaken self-correcting mechanisms, then a faster flow of information can only marginally improve the consumers' self learning procedure and as a result the cost of running these institutions may exceed the benefit they provide;

(b) From the above it follows that if the self-correcting mechanism of the consumers and the existence of the good businessman can drive out the bad businessman from the market then consumer loss will be short lived and will be confined to a relatively small portion of the total consumers. Therefore the cost of permanent maintenance of these organizations will exceed the benefit they can provide;

(c) The existence of such organizations may encourage consumers to exclusively rely on those institutional factors for information, rather than to rely upon deceived consumers to inform them about the dishonest businessman, then the consumer protection authority can only inform consumers about those incidence that are reported, while information about unreported ones would not be passed onto other consumers, thereby allowing many dishonest businessmen to survive longer than it would have been possible in the absence of these organizations. Therefore this suggests that the flow of information will be slower than it would be in the absence of such organizations. Consumers only report those incidences where loss has a greater magnitude and the consumers are prepared to claim compensation, that is in general they do not inform about small incidences. Thus it then allows many dishonest businessmen to survive longer since the majority of the consumers remain uninformed and they are likely to be deceived. Furthermore, as we have legal institutions to take care of the dishonest businessman, additional organizations can hardly add much to these procedures.

\section{References:}

[1]. Arrow, K,J. (1962), The Economic Implications of Learning by Doing, Review of Economic Studies, Vol. 29.

[2]. Arrow, K,J. (1968), Political and Economic Evaluation of Social Effects and Externalities" in Frontiers of Quantitative Economics (Ed) M.D. Intriligator, North Holland Publishing Company.

[3]. Diamond, P. (1971), A Model of Price Adjustment, Journal of Economic Theory, 3, P 136.-168.

[4]. Fisher, F.M. (1970), Quasi-Competitive Price Adjustment by Individual Firms: A Preliminary Paper, Journal of Economic Theory, 3, P. 195-206.

[5]. Salop, S. (1977), The Noisy Monopolist: Imperfect Information, Price Dispersion and Price Discrimination, Review of Economic Studies, 44, P. 393-406.

[6]. Salop, S. \& J. Stiglitz (1977), Bargain \& Rip-Offs: A Model of Monopolistically Competitive Price-Dispersion, Review of Economic Studies, 44, P. 493-510.

[7]. Stiglitz, J.E. (1987), The Causes and consequence of the dependence of quality on price, Journal of Economic Literature, Vol. XXV, No. 1, March, P. 1-49. 